\title{
Prediction of adaptive self-regulatory responses to arthritis pain anxiety in exercising adults: Does pain acceptance matter?
}

\author{
Miranda A Cary MSc, Nancy C Gyurcsik PhD, Lawrence R Brawley PhD
}

\begin{abstract}
MA Cary, NC Gyurcsik, LR Brawley. Prediction of adaptive selfregulatory responses to arthritis pain anxiety in exercising adults: Does pain acceptance matter? Pain Res Manag 2015;20(2):67-74.
\end{abstract}

BACKGROUND: Exercising for $\geq 150 \mathrm{~min} /$ week is a recommended strategy for self-managing arthritis. However, exercise nonadherence is a problem. Arthritis pain anxiety may interfere with regular exercise. According to the fear-avoidance model, individuals may confront their pain anxiety by using adaptive self-regulatory responses (eg, changing exercise type or duration). Furthermore, the anxiety-self-regulatory responses relationship may vary as a function of individuals' pain acceptance levels.

OBJECTIVES: To investigate pain acceptance as a moderator of the pain anxiety-adaptive self-regulatory responses relationship. The secondary objective was to examine whether groups of patients who differed in meeting exercise recommendations also differed in pain-related and selfregulatory responses.

METHODS: Adults (mean [ \pm SD] age $49.75 \pm 13.88$ years) with medically diagnosed arthritis completed online measures of arthritis pain-related variables and self-regulatory responses at baseline, and exercise participation two weeks later. Individuals meeting $(n=87)$ and not meeting $(n=49)$ exercise recommendations were identified.

RESULTS: Hierarchical multiple regression analysis revealed that pain acceptance moderated the anxiety-adaptive self-regulatory responses relationship. When pain anxiety was lower, greater pain acceptance was associated with less frequent use of adaptive responses. When anxiety was higher, adaptive responses were used regardless of pain acceptance level. MANOVA findings revealed that participants meeting the recommended exercise dose reported significantly lower pain and pain anxiety, and greater pain acceptance $(\mathrm{P}<0.05)$ than those not meeting the dose.

CONCLUSIONS: Greater pain acceptance may help individuals to focus their efforts to adapt to their pain anxiety only when it is higher, leaving self-regulatory capacity to cope with additional challenges to exercise adherence (eg, busy schedule).

Key Words: Arthritis; Exercise; Pain acceptance; Pain anxiety; Self-regulation

A thritis is one of the most common chronic diseases in Canada, affecting 4.2 million people (1). Public health agencies and arthritis organizations recommend that adults with all types of arthritis can more effectively self-manage their disease through regular exercise (1-3). Recommendations state that adults should engage in $\geq 150 \mathrm{~min}$ of moderate to vigorous exercise each week $(1,2)$. However, up to $60 \%$ of individuals with arthritis do not exercise regularly (1). Identifying modifiable psychosocial factors, which are informed by theory, that are associated with exercise is key to the design of future interventions aimed at increasing adherence (4).

According to social cognitive theory (5), exercise is a freely chosen, motivated and planned behaviour that requires self-regulation.
Prédire les réponses d'autorégulation adaptatives à l'anxiété vis-à-vis de la douleur arthritique chez les adultes qui font de l'exercice : l'acceptation de la douleur importe-t-elle?

HISTORIQUE : Il est recommandé de faire de l'exercice au moins 150 minutes par semaine pour autogérer l'arthrite, mais cette recommandation est peu respectée. L'anxiété vis-à-vis de la douleur arthritique nuit peutêtre à l'exercice régulier. D'après le modèle d'évitement de la douleur, les personnes peuvent affronter leur anxiété vis-à-vis de la douleur au moyen de réponses d'autorégulation adaptatives (p. ex., changer le type ou la durée de l'exercice). De plus, le rapport entre l'anxiété et la réponse d'autorégulation peut varier en fonction du taux d'acceptation de la douleur.

OBJECTIFS : Examiner l'acceptation de la douleur comme modérateur du rapport entre l'anxiété et la réponse d'autorégulation. L'objectif secondaire consistait à examiner si les groupes de patients qui respectaient différemment les recommandations relatives à l'exercice différaient également dans leurs réponses liées à la douleur et leurs réponses d'autorégulation. MÉTHODOLOGIE : Les adultes (âge moyen [ \pm ÉT] de 49,75 $\pm 13,88$ ans) atteints d'une arthrite diagnostiquée ont transmis en ligne leurs mesures de douleur arthritique et leurs réponses d'autorégulation en début d'étude, puis leur participation à l'exercice deux semaines plus tard. Les chercheurs ont déterminé les personnes qui respectaient $(n=87)$ ou non $(n=49)$ les recommandations liées à l'exercice.

RÉSULTATS : L'analyse de régression hiérarchique multiple a révélé que l'acceptation de la douleur modérait le rapport entre l'anxiété et la réponse d'autorégulation. Lorsque l'anxiété vis-à-vis de la douleur était moins élevée, une meilleure acceptation de la douleur s'associait à un moindre recours aux réponses adaptatives. Lorsque l'anxiété était plus élevée, les patients recouraient aux réponses adaptatives, quel que soit leur taux d'acceptation de la douleur. D'après l'analyse de variance multivariée, les participants qui respectaient les recommandations relatives à l'exercice signalaient ressentir beaucoup moins de douleur et d'anxiété vis-à-vis de la douleur et mieux accepter la douleur $(\mathrm{P}<0,05)$ que ceux qui ne respectaient pas les recommandations.

CONCLUSIONS : Une meilleure acceptation de la douleur peut contribuer à concentrer les efforts pour s'adapter à l'anxiété vis-à-vis de la douleur seulement lorsque celle-ci est élevée et à réserver la capacité d'autorégulation aux autres problèmes liés au respect des recommandations (p. ex., un horaire chargé).

Self-regulation involves individuals controlling their thoughts, behaviours and/or feelings to perform planned exercise in the face of challenges (6). That is, the need to self-regulate becomes important when individuals are challenged by factors that make it difficult to exercise as planned (eg, a busy schedule, lack of motivation, increases in arthritis symptoms such as pain). To successfully persist in overcoming challenges and adhere to planned exercise, social cognitive theory contends that individuals should use adaptive self-regulatory responses (5). These types of responses involve individuals changing their thoughts, behaviours and/or feelings to help them overcome challenge(s) to their planned exercise.

Among the arthritis population, research has supported the theoretical contention that adaptive responses help individuals effectively

College of Kinesiology, University of Saskatchewan, Saskatoon, Saskatchewan

Correspondence: Ms Miranda A Cary, College of Kinesiology, University of Saskatchewan, 87 Campus Drive, Saskatoon, Saskatchewan S7N 5B2.

Telephone 306-966-1075, fax 306-966-6464, e-mail miranda.cary@usask.ca 
cope with exercise challenges. For example, both inactive and exercising adults reported experiencing similar arthritis-related challenges to exercise such as a lack of mobility and fear of experiencing pain. However, individuals who exercised, including those meeting the recommended dose, used self-regulatory responses to effectively cope with their challenges and continue to exercise as planned (7-11). Examples of self-regulatory responses most often reported and used by patients with arthritis to deal with challenges included modifying exercise by reducing the duration, frequency and/or specific type of exercise that was planned, as well as performing planned exercise regardless of barriers (often referred to as 'just do it') (7-11). These responses are adaptive in that they help individuals continue to exercise, albeit at reconfigured levels at times (eg, shorter duration, lower intensity), which can still result in meeting exercise recommendations (11). In fact, reconfiguring exercise plans is a recommended overall strategy to help individuals to continue to exercise when faced with the challenge of experiencing an arthritis flare (12). In contrast, nonexercisers used maladaptive responses to barriers, most often involving the discontinuation of exercise $(7,8,10)$. Given the association between adaptive self-regulatory responses to barriers and exercise, it would be instructive to identify factors that predict the use of such responses. One such factor may be pain anxiety.

\section{Arthritis pain and pain anxiety}

Arthritis pain is one of the most frequently reported barriers to exercise $(11,13,14)$. However, pain neither predicts exercise nor differentiates adults meeting the recommended exercise dose from those who exercise less (11,13-15). Suggestions from the larger chronic pain literature are that psychosocial responses to pain, versus pain itself, may determine whether individuals engage in valued activities such as exercise $(16,17)$.

Anxiety is a common response to arthritis pain $(9,18,19)$. Pain anxiety is a future-oriented affective state involving anticipation of pain or injury when intending to engage in planned activities (20-22). The fear-avoidance model of pain provides insight on how pain anxiety may influence whether individuals engage in valued activities $(23,24)$.

\section{Fear-avoidance model of pain}

The fear-avoidance model postulates that individuals may engage in one of two behavioural response pathways to their pain and anxiety: avoidance (maladaptive) or confrontation (adaptive) $(25,26)$. Avoidance is a maladaptive pathway in which individuals negatively interpret their pain, leading to increases in pain anxiety and avoidance behaviours (27). In contrast, confrontation is an adaptive pathway that leads to continued participation in valued activities such as exercise $(22,24,28)$. The confrontation pathway has received limited research attention to date and was the focus of the present study.

According to the fear-avoidance model, individuals confront their pain and anxiety by engaging in adaptive self-regulatory responses (24). Furthermore, pain resiliency, reflected, in part, by individuals having greater pain acceptance, may help people to confront their anxiety $(24,28)$. Pain acceptance involves a willingness to engage in valued activities without efforts to control or reduce pain (29). Individuals with greater pain acceptance appear to be able to function and engage in valued activities despite their pain, in contrast to those less accepting of pain $(24,30)$. For example, adults with arthritis who had greater levels of pain acceptance were also those who met the recommended exercise dose (13).

When considered relative to the fear-avoidance model, pain acceptance may serve as a moderator of the pain anxiety-adaptive selfregulatory responses relationship (24). Applying complementary perspectives from the motivational aspect of the fear-avoidance model (25) and the self-regulatory view of social cognitive theory (5), individuals with greater pain acceptance may use adaptive self-regulatory responses only when needed; that is, when their pain anxiety is more challenging/higher (24). Alternatively, less pain anxiety may not be perceived by those with greater pain acceptance as a challenge to exercise, thereby requiring little to no adaptation. In contrast, those with lower levels of pain acceptance may regard their pain anxiety as a challenge at all times that requires attempts at adaptation.

\section{Study objectives}

No research to date has examined the moderation of the pain anxiety-adaptive self-regulatory responses relationships in the arthritis-exercise research literature. The primary objective was to determine whether pain acceptance moderated the relationship between pain anxiety and adaptive self-regulatory responses to this anxiety among exercising adults with arthritis. Pain acceptance was hypothesized to be a moderator $(13,24,31)$.

Given the importance of adherence to exercise for arthritis selfmanagement (1), a secondary objective was to determine whether participants meeting or not meeting the recommended exercise dose $(\geq 150 \mathrm{~min} /$ week) differed with respect to their arthritis pain, pain anxiety, pain acceptance and self-regulatory responses. Individuals exercising at the recommended dose were expected to express less pain anxiety, greater pain acceptance and use adaptive self-regulatory responses more frequently than those not meeting the dose $(13,24,32)$. No differences in pain were expected $(11,13-15)$.

\section{Participants and procedures}

\section{METHODS}

Participants in the present two-week prospective study were 136 adults with self-reported medically diagnosed arthritis. After approval by the University Behavioural Research Ethics Board, participants were recruited via Internet- and paper-based study announcements that were e-mailed to Internet-based arthritis chat groups and national arthritis organizations in Canada and in the United States (The Arthritis Society, The Arthritis Foundation), posted at local gyms and fitness centres, and distributed via in-person visits to local community-based exercise programs designed for adults with arthritis. Study announcements directed participants to an online link to the baseline survey.

Once individuals provided electronic informed consent, questions about participant inclusion criteria were completed, which included: age $\geq 18$ years; residing in Canada or in the United States; Englishspeaking; having self-reported medically diagnosed arthritis, which was an appropriate and valid assessment method for survey-based research (33); plans to participate in $\geq 20$ min bouts of moderate to vigorous exercise each week over the subsequent two-week study period; an immediate history of moderate to vigorous exercise for $\geq 20 \mathrm{~min}$ at one time over the previous two weeks; and reported experiencing arthritis pain and pain anxiety (ie, reported $>0$ on at least one item on each measure).

Information regarding participants' type of arthritis (eg, osteoarthritis) was not obtained, given that individuals do not accurately recall or know such information (34). Also, some exercise is recommended for all arthritis types, even during flares (12). Requiring participants to have immediate past experiences and plans to exercise ensured that they could offer experience-based responses to the exercise-related psychosocial measures in the study. Focusing participants on a planned minimum 20 min exercise bout ensured that they had to consciously self-regulate their activity, a necessity for the examination of self-regulatory responses. Shorter bouts of incidental exercise would not require conscious weekly planning and self-regulation, and would have been subject to recall errors (5). Planned bouts of longer duration were more apt to be recalled and selfreported with accuracy (ie, more strongly correlated with objective measures) versus light exercise and/or short-duration bouts of unplanned activity $(35,36)$. Ensuring that participants had arthritis pain and pain anxiety were also required to investigate the primary study objective, which focused on relationships between pain anxiety, pain acceptance and self-regulatory responses.

Individuals who met the criteria completed the baseline survey, which took $20 \mathrm{~min}$ to $30 \mathrm{~min}$ to complete, and assessed participant demographics, pain-related variables (intensity, anxiety and acceptance) and self-regulatory responses. A link to the follow-up survey was 
emailed to the participants two weeks later. This 3 min to 5 min survey assessed participants' moderate and vigorous exercise over the previous two weeks. Individuals who completed both surveys were included in the study. Exercise group categorization for the secondary objective was based on the follow-up exercise response.

\begin{abstract}
Measures
Pain intensity: Participants rated their arthritis pain in four instances: "during a typical day", "during a typical flare", "when not in a flare" and "at the present moment". Responses were on a 0 (no pain) to 10 (extreme pain) scale. A mean score was calculated for each participant. The measure has been used in previous arthritis-exercise research, demonstrating acceptable internal consistency $(11,13)$ and follows recommendations for assessing chronic pain (37). The measure was internally consistent in the present study $(\alpha=0.88)$ (38).

Pain anxiety: The Pain Anxiety Symptoms Scale (PASS-20) assessed arthritis-related pain anxiety (39). The PASS-20 consists of four subscales with five items each: cognitive anxiety symptoms (eg, "I can't think straight when in arthritis pain”); escape/avoidance behaviours (eg, "I avoid important activities when I hurt"); fearful responses to pain (eg, "Arthritis pain sensations are terrifying"); and physiological arousal in response to pain (eg, "When I sense arthritis pain, I feel dizzy or faint"). "Arthritis" was inserted immediately before "pain" in each PASS-20 item to focus participants' responses about diseaserelated anxiety, versus anxiety from other sources. Participants were instructed to think about when they experienced arthritis pain and were planning to do moderate to vigorous exercise. The extent to which each PASS item was a true description of the participant on a 0 (never) to 5 (always) scale was obtained. An overall summed pain anxiety score was calculated, with the potential range being 0 to 100 (higher scores represented higher anxiety) $(29,40)$. The PASS-20 has established reliability and validity (39), and was internally consistent in the present study $(\alpha=0.93)$ (38).
\end{abstract}

Pain acceptance: The Chronic Pain Acceptance Questionnaire (CPAQ) assessed arthritis pain acceptance (29). The CPAQ is comprised of two subscales: an 11-item activities engagement scale assessed the extent to which people pursue life activities despite having pain (eg, "I am getting on with the business of living no matter what my level of arthritis pain is"); and a nine-item pain willingness scale that assessed people's willingness to experience pain without any control attempts (eg, "I need to concentrate on getting rid of my arthritis pain"). Consistent with previous research (12), "arthritis" was inserted before "pain" in each item to encourage participants' focus on their arthritis pain. Participants rated the truth of each item on a 0 (never true) to 6 (always true) scale. A total pain acceptance score was calculated by first reverse scoring the pain willingness subscale items and then summing the items of both subscales (29). The total possible response range was 0 to 120 , with higher scores representing greater pain acceptance. The CPAQ is a reliable and valid measure (29), has been used with other chronic disease samples attempting to adhere to exercise for disease management (eg, peripheral artery disease) (41) and was internally consistent in the present study $(\alpha=0.90)$ (38).

Adaptive self-regulatory responses to pain anxiety: A five-item measure was developed for use in the present study. Items were based on past arthritis, exercise and chronic pain research that reported on behavioural self-regulatory strategies used by individuals to deal with pain and/or anxiety $(7,11,24,42)$. The items concerned the following strategies: "Alternate the type of exercise that you planned on doing", "Change the type of exercise you planned on doing", "Do less exercise than planned", "Make efforts to relax to reduce tension" and "Use heat or ice before/after planned exercise".

An additional behavioural self-regulatory response was also identified in the past research ("Do all of your scheduled/planned exercise, regardless of your pain anxiety") (11). This response was initially included as an adaptive item in the present study. However, initial analysis of Cronbach's alpha revealed that this item reduced the internal consistency of the adaptive measure to an unacceptable level $(\alpha<0.60)$ (38). This item was kept in the study, given its reporting in past research as an effective behavioural approach, and was termed a "maintenance self-regulatory response". On a conceptual basis, this item is not truly an adaptation to pain anxiety but a maintenance of current behaviour (ie, exercise as planned - 'just do it'), further justifying its individual use. Considering the fearavoidance model and the potential of a maintenance self-regulatory response to help people confront pain anxiety, moderation of its relationship with pain anxiety by pain acceptance was also investigated in the present study.

For both of the adaptive and maintenance measures, participants rated the extent to which they would use each response when anticipating pain anxiety in relation to planned exercise over the next two weeks. Responses were on a 0 (never do this) to 8 (always do this) scale. The adaptive items were summed, resulting in a potential response range of 0 to 40 . Higher scores represented more frequent use of adaptive responses. The adaptive measure was internally consistent in the present study ( $\alpha=0.65$ ) (38). The maintenance item was used as a single value.

Exercise: Participants reported the frequency and average duration of actual $\geq 20$ min bouts of each of their planned moderate and vigorous exercise during the previous two weeks. A total exercise volume was calculated in a manner consistent with international recommendations and previous research involving adults with arthritis $(1,11,13,43)$. Before completing the measure, participants read definitions of moderate and vigorous exercise $(2,43,44)$. Moderate exercise was defined as "...makes your heart beat faster and makes you breathe a little harder. You can talk easily while doing moderate exercise, but you may not be able to sing comfortably. On a scale from 0 to 10 , where sitting is 0 and the highest level of effort possible is 10 , moderate exercise is a 5 or 6". Vigorous exercise was defined as “... makes your heart beat much faster. You may not be able to talk comfortably without stopping to catch your breath. On a scale of 0 to 10 , where sitting is 0 and the highest level of effort possible is 10 , vigorous exercise is a 7 or $8 . "$

After reading the definitions, participants reported their average weekly number of days (ie, frequency) over the previous two weeks that they were active for a planned $\geq 20 \mathrm{~min}$ for each of moderate and vigorous exercise, followed by their average exercise duration at each intensity. Total exercise volume per week was calculated by summing total moderate exercise (frequency $\times$ duration) with total vigorous exercise (frequency $\times$ duration $\times 2$ ). Multiplying vigorous exercise $\times 2$ follows guidelines for the conversion into moderate-equivalent minutes (44).

\section{Statistical analyses}

The analytical plan addressed demographics and the primary and secondary study objectives as follows. First, demographics of the full sample as well as according to exercise group were examined. Second, to address the primary objective and hypotheses, hierarchical multiple regression analyses were conducted to investigate the prediction of adaptive self-regulatory responses and the maintenance selfregulatory response. Before each analysis was conducted, assumptions were verified and met (45). In both regression models, pain was entered as a covariate in step 1 to control for any association it may have had with the outcome variable.

The first regression analysis to predict adaptive responses had two additional steps. Because pain acceptance was examined as a moderator of the pain anxiety-adaptive self-regulatory responses relationship, both of the anxiety and acceptance predictor variables were centred to reduce multicollinearity (46-48). Then, the centred pain anxiety and pain acceptance variables were entered in step 2 , followed by the centred interaction term (centred pain anxiety $\times$ centred pain acceptance) in step 3. If a significant interaction was found, then simple slopes analyses were planned to investigate the effect (46). The second hierarchical regression analysis to investigate predictors of the maintenance selfregulatory response was conducted in a similar manner. 
TABLE 1

Demographic characteristics of the study participants

\begin{tabular}{|c|c|c|c|}
\hline Characteristic & $\begin{array}{l}\text { Full sample } \\
(n=136)\end{array}$ & $\begin{array}{r}\text { Met exercise } \\
\text { dose }(n=87)\end{array}$ & $\begin{array}{l}\text { Did not meet exercise } \\
\text { dose }(n=49)\end{array}$ \\
\hline Age, years, mean $\pm S D$ & $49.75 \pm 13.88$ & & $50.33 \pm 14.06$ \\
\hline $\begin{array}{l}\text { Body mass index, } \mathrm{kg} / \mathrm{m}^{2}, \\
\text { mean } \pm \mathrm{SD}\end{array}$ & $28.18 \pm 7.17$ & & $29.26 \pm 7.16$ \\
\hline \multicolumn{4}{|l|}{ Sex } \\
\hline Female & $116(85)$ & $75(86)$ & $41(84)$ \\
\hline Male & $17(13)$ & $11(13)$ & $6(12)$ \\
\hline \multicolumn{4}{|l|}{ Ethnicity } \\
\hline White & $126(93)$ & $81(93)$ & $46(94)$ \\
\hline Chinese & $3(2)$ & $3(2)$ & - \\
\hline Latin American & $3(2)$ & $2(2)$ & $1(2)$ \\
\hline Native & $1(1)$ & - & $1(2)$ \\
\hline Multiracial & $2(1)$ & $1(1)$ & $1(2)$ \\
\hline \multicolumn{4}{|c|}{ Number of years diagnosed with arthritis } \\
\hline$<1$ & $11(8)$ & $8(9)$ & $3(6)$ \\
\hline $1-5$ & $41(30)$ & $24(28)$ & $17(35)$ \\
\hline $6-10$ & $31(23)$ & $20(23)$ & $11(22)$ \\
\hline $11-15$ & $19(14)$ & $15(17)$ & $4(8)$ \\
\hline $16-20$ & $10(7)$ & $7(8)$ & $3(6)$ \\
\hline$>20$ & $24(18)$ & $13(15)$ & $11(22)$ \\
\hline \multicolumn{4}{|c|}{ Limitation in activities due to arthritis } \\
\hline Yes & $102(75)$ & $57(66)$ & $45(92)$ \\
\hline No & $28(20)$ & $25(29)$ & $3(6)$ \\
\hline Do not know & $5(4)$ & $4(5)$ & $1(2)$ \\
\hline \multicolumn{4}{|c|}{ Medication to control arthritis } \\
\hline Yes & $114(85)$ & $71(82)$ & $44(90)$ \\
\hline No & $22(16)$ & $16(18)$ & $5(10)$ \\
\hline
\end{tabular}

Data presented as $n(\%)$ unless otherwise indicated. Full data for the 136 participants are not reported due to missing values for $\operatorname{sex}(n=3)$, ethnicity $(n=1)$, education ( $n=2)$ and limitation in activities due to arthritis $(n=1)$

To address the secondary study objective and hypotheses, exercise groups were identified as follows. Based on exercise recommendations $(1,2)$ and similar to previous research (14), two groups were identified: participants who met the dose engaged in $\geq 150 \mathrm{~min} /$ week and participants who did not meet the dose engaged in $<150 \mathrm{~min} / \mathrm{week}$. A $t$ test was then conducted to empirically verify that the two groups significantly differed in their exercise volume and that comparisons could proceed with empirically different exercise groups.

The two exercise groups were examined for differences in continuous demographic characteristics (age and body mass index) via MANOVA, and in categorical demographic characteristics (eg, sex) via $\chi^{2}$ analyses. Tests were conducted to identify whether any preexisting demographic differences existed between the two exercise groups and, thus, would have to be controlled for in the investigation of the secondary objective (45).

Recall that the aim was to examine whether participants who met versus those who did not meet the recommended exercise dose differed in their pain-related variables and self-regulatory responses (adaptive and maintenance responses). Between-exercise group differences in demographic characteristics were first examined, as mentioned previously, to determine whether there were any relevant covariates that should be controlled using MANCOVA. If none were evident, then two separate one-way between-groups MANOVAs were planned. The first MANOVA examined whether the two exercise groups (met versus did not meet) differed in their pain-related psychosocial factors (ie, pain, anxiety and acceptance). The second MANOVA examined whether the two exercise groups differed in the behavioural variables of adaptive and maintenance self-regulatory responses.

Before conducting the multivariate analyses, assumptions were checked and met (45). Multicollinearity among the dependent variables was examined and was not problematic. All significant omnibus multivariate effects were further investigated via ANOVA analyses to identify the dependent variables that significantly differed between the exercise groups.

\section{RESULTS}

Establishing exercise groups

A total of 87 participants met the recommended exercise dose and 49 participants did not. A $t$ test to empirically verify between-group differences in exercise volume was significant $(\mathrm{t}[134]=-11.71$, $\mathrm{P}<0.001$; met the dose, mean $[ \pm \mathrm{SD}] 366.24 \pm 231.59 \mathrm{~min} /$ week; did not meet the dose, mean $64.78 \pm 47.76 \mathrm{~min} /$ week).

\section{Participant demographics}

Table 1 presents demographics for the full sample as well as according to exercise group. The mean \pm SD age of the 136 participants was $49.75 \pm 13.88$ years. Participants were predominantly female $(n=116)$ and white $(\mathrm{n}=126)$, with a self-reported body mass index of $28.18 \pm 7.17 \mathrm{~kg} / \mathrm{m}^{2}$. Furthermore, $62 \%$ of the sample had been diagnosed with arthritis by a medical professional for $\geq 6$ years, $75 \%$ reported limitation in their activities due to arthritis and $84 \%$ took medication to control their disease.

A MANOVA comparing the two exercise groups with regard to age and body mass index was not significant $(F[2,133]=0.95$, Pillai's Trace $=$ $0.01 ; \mathrm{P}>0.05) \cdot \chi^{2}$ analyses comparing the two exercise groups in their categorical demographics were not significant $(\mathrm{P}>0.05)$. This analysis did not reveal possible covariates to be considered in analyses for the secondary objective, which is presented later in the Results section.

\section{Predicting adaptive self-regulatory responses}

In step 1, pain was a significant predictor of adaptive self-regulatory responses $(F[1,134]=11.51 ; P=0.001)$ (Table 2). Including the two centred predictor variables of pain anxiety and pain acceptance in step 2 resulted in a significant model $(\mathrm{F}[3,132]=10.65 ; \mathrm{P}<0.001)$. Adding the centred interaction variable (pain anxiety $\times$ pain acceptance) in step 3 contributed an additional and significant $3 \%$ variance to the model. The full model was significant ( $F[4,131]=9.57$; $\mathrm{P}<0.001$ ), accounting for $20 \%$ of the variance in adaptive selfregulatory responses.

As hypothesized, the interaction term was a significant, independent predictor. The effect size of this interaction was small (Table 2) (49). Given the significant interaction, simple slopes analyses were conducted (Figure 1). Results revealed that the regression line for those with lower pain acceptance was not significantly different than zero $(t[131]=0.18 ; P=0.86)$. However, the regression line for those with greater pain acceptance was significantly different than zero $(t[131]=2.44 ; P=0.02)$. Figure 1 shows that participants with greater pain acceptance used adaptive self-regulatory responses less often when pain anxiety was lower than those with lower pain acceptance. However, when pain anxiety was higher, both lower and higher pain acceptance were associated with more frequent use of adaptive selfregulatory responses.

\section{Predicting maintenance self-regulatory response}

In step 1 of the hierarchical multiple regression analysis predicting the maintenance self-regulatory response, pain was not a significant predictor $(F[1,134]=0.70 ; \mathrm{P}=0.40)$ (Table 3 ). Including the two centred predictor variables of pain anxiety and pain acceptance in step 2 resulted in a significant model $(F[3,132]=15.86 ; \mathrm{P}<0.001)$. With the addition of the centred pain anxiety $\times$ pain acceptance interaction in step 3, the overall model was significant $(F[4,131]=11.81 ; \mathrm{P}<0.001)$. However, the interaction term did not contribute additional significant variance to the model $(\mathrm{P}=0.89)$. Pain acceptance was the sole significant predictor of the maintenance self-regulatory response, representing a large effect size (effect size values presented in Table 3) (49). As pain acceptance increased, participants also reported an associated increase in their use of the maintenance response. 
TABLE 2

Predicting adaptive self-regulatory responses

\begin{tabular}{lccc}
\hline Predictor & $\begin{array}{c}\mathbf{R}^{2} \text { Adjusted } \\
\text { Model }\end{array}$ & $\mathbf{R}^{2} \boldsymbol{\Delta}$ & $\mathbf{B}_{\text {standardized }}$ \\
\hline Step 1 & $0.07^{*}$ & & $0.28^{\dagger}$ \\
$\quad$ Pain & & & \\
Step 2 & $0.18^{\dagger}$ & $0.12^{\dagger}$ & \\
Pain & & & $0.19^{*}$ \\
Pain anxiety & & & 0.12 \\
Pain acceptance & $0.20^{*}$ & $0.03^{*}$ & $-0.26^{*}$ \\
Step 3 & & & \\
Pain & & & $0.20^{*}$ \\
Pain anxiety & & & 0.19 \\
Pain acceptance & & & -0.20 \\
Pain anxiety $\times$ pain acceptance & & & $0.18^{*}$ \\
\hline
\end{tabular}

Pain anxiety, pain acceptance and the interaction term were centred variables.

$B_{\text {standardized }}=$ effect size. ${ }^{*} P<0.05 ;{ }^{\dagger} P<0.001$

Exercise group differences in pain-related and self-regulatory responses

Given that pre-existing between-exercise group differences in demographics (ie, possible covariates) were not found, the secondary objective analysis involved two separate between-groups MANOVAs. The overall MANOVA comparing the exercise groups across painrelated variables (intensity, anxiety and acceptance) was significant $(\mathrm{F}[3,132]=6.78 ;$ Pillai's Trace $=0.13 ; \mathrm{P}<0.001)$ (variable means and SDs according to group as well as for the effect size values are presented in Table 4). Follow-up ANOVAs illustrated that, as expected, the group meeting the exercise dose had significantly lower pain anxiety $(\mathrm{F}[1,134]=5.86 ; \mathrm{P}<0.05)$ and higher pain acceptance $(\mathrm{F}[1,134]=17.75 ; \mathrm{P}<0.001)$ compared with those not meeting the dose. Contrary to expectations, the two exercise groups also significantly differed in their arthritis pain $(\mathrm{F}[1,134]=5.73 ; \mathrm{P}<0.05)$. Those who met the exercise dose reported significantly lower pain than those not meeting the dose.

The second MANOVA examining exercise group differences in the self-regulatory adaptive and maintenance responses was also significant $(\mathrm{F}[2,133]=8.18$; Pillai's Trace $=0.11 ; \mathrm{P}<0.001)$ (variable means and SDs according to group as well as for the effect size values are presented in Table 5). Follow-up ANOVAs revealed that, contrary to the study hypothesis, the two groups did not significantly differ in their use of adaptive self-regulatory responses $(F[1,134]=2.26$; $\mathrm{P}>0.05)$. However, those who met the exercise dose reported using the maintenance self-regulatory response significantly more often than the group not meeting the dose $(\mathrm{F}[1,134]=16.43 ; \mathrm{P}<0.001)$.

\section{DISCUSSION}

The present study contributed three novel findings. First, in support of the primary hypothesis, pain acceptance moderated the pain anxietyadaptive self-regulatory responses relationship. Second, pain acceptance was the sole predictor of the maintenance self-regulatory response. Third, as expected, participants meeting the recommended exercise dose reported significantly less pain anxiety and greater pain acceptance than those not meeting the dose. The former participants also reported using the maintenance response most often. In contrast to expectations, the exercise groups did not differ in their use of adaptive self-regulatory responses; however, the two exercise groups differed in their reporting of pain intensity.

Study findings provided the first evidence in the arthritis-exercise domain that pain acceptance was a significant moderator of the pain anxiety-adaptive self-regulatory responses relationship. Follow-up analyses illustrated that lower pain anxiety predicted less frequent use of adaptive responses when pain acceptance was higher, compared with when pain acceptance was lower. However, when pain anxiety was higher, both lower and higher pain acceptance were associated with more frequent use of adaptive self-regulatory responses.

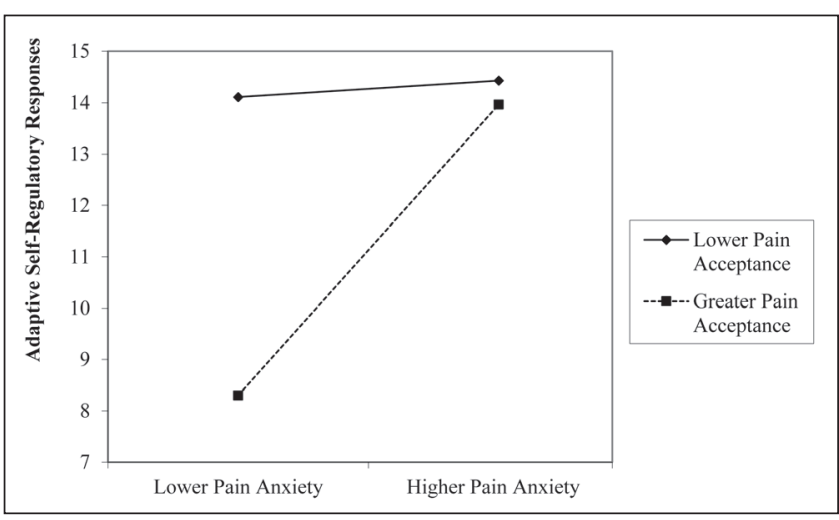

Figure 1) Interaction of pain anxiety $\times$ pain acceptance predicting adaptive self-regulatory responses

\section{TABLE 3}

Predicting the maintenance self-regulatory response

\begin{tabular}{lccc}
\hline Predictor & $\begin{array}{c}\mathbf{R}^{2} \text { Adjusted } \\
\text { Model }\end{array}$ & $\mathbf{R}^{2} \boldsymbol{\Delta}$ & $\mathbf{B}_{\text {standardized }}$ \\
\hline Step 1 & 0.005 & & \\
Pain & & & -0.07 \\
Step 2 & $0.25^{*}$ & $0.26^{*}$ & \\
Pain & & & 0.07 \\
Pain anxiety & & & -0.13 \\
Pain acceptance & $0.24^{*}$ & 0.03 & $0.43^{*}$ \\
Step 3 & & & \\
Pain & & & 0.07 \\
Pain anxiety & & & 0.13 \\
Pain acceptance & & $0.47^{*}$ \\
Pain anxiety $\times$ pain acceptance & & 0.01 \\
\hline
\end{tabular}

Pain anxiety, pain acceptance, and the interaction term were centered variables. $B_{\text {standardized }}=$ effect size. ${ }^{*} P<0.001$

Complementary perspectives from the social cognitive theory idea of self-regulation and the fear-avoidance model suggest a possible explanation of the moderator effect. Confrontation should occur when individuals are challenged by pain anxiety and have the self-regulatory strength to persist in overcoming this challenge $(22,50)$. Having greater pain acceptance should help individuals to regard higher pain anxiety as a challenge that requires adaptation (24). In contrast, when pain anxiety is lower and not challenging, individuals with greater pain acceptance should make little effort to adapt, allowing themselves to engage in their valued activities $(24,29)$.

In contrast, individuals expressing lower pain acceptance may view pain anxiety at all levels as a challenge, consequently requiring adaptation (51). This is a paradox, however, in that constant adaptation drains self-regulatory capacity $(6,51)$. The draining of capacity causes individuals to reduce their adaptation efforts, requiring rest to replenish their self-regulatory strength. Consequently, adherence may be reduced. Indeed, research has demonstrated that individuals fail to persist when their self-regulatory strength has been experimentally drained (6).

The foregoing explanations are suggestions as to what the observed interaction represented based on the complementary perspectives of social cognitive theory and the fear-avoidance model $(5,24)$. However, experimental testing would be required for verification. It should be noted that detection of the interaction, while interesting and promising, reflects a small effect size (49). This was an exercising sample with years of experience living with their disease. For these individuals, pain anxiety may not be a strong enough challenge to contribute to complete nonadherence. Observation of the mean values for pain anxiety indicates that participants reported levels that were not overly challenging (ie, lower one-third of the 0 to 100 response range). 
TABLE 4

Differences in pain-related variables among participants who met versus did not meet the exercise dose

\begin{tabular}{lccc}
\hline Variable & Met dose $(\mathbf{n = 8 7})$ & $\begin{array}{c}\text { Did not meet } \\
\text { dose }(\mathbf{n = 4 9})\end{array}$ & Cohen's d \\
\hline Pain* $^{*}$ & $4.37 \pm 1.84$ & $5.18 \pm 2.00$ & 0.42 \\
Pain anxiety* $^{*}$ Pain acceptance $^{\dagger}$ & $25.92 \pm 18.01$ & $34.58 \pm 19.21$ & 0.43 \\
\hline
\end{tabular}

Data presented as mean $\pm S D$ unless otherwise indicated. Scale response were: pain: 0 (no pain) to 10 (extreme pain); pain anxiety: 0 to 100, with higher scores representing more anxiety; and pain acceptance: 0 to 120, with higher scores representing greater acceptance. Cohen's $d=$ effect size. Betweengroup differences within a row, ${ }^{*} P<0.05,{ }^{\dagger} P<0.01$

However, the lower anxiety scores were comparable with other clinical and nonclinical samples $(22,39,52)$.

Regarding the secondary objective, participants meeting the exercise dose did not report greater use of adaptive self-regulatory responses than those not meeting the dose. While this finding contrasted with the study hypothesis, the more frequent use of the maintenance selfregulatory response may offer an explanation. More active participants may have simply engaged in doing what they had planned without additional adaptation.

We found that that the two exercise groups differed in their perceived arthritis pain, which contrasts with other arthritis-exercise evidence $(14,17)$. Using the same pain measure, Gyurcsik et al (14) found that exercising adults with arthritis had similar arthritis pain levels, regardless of whether they were exercising at $\geq 150 \mathrm{~min} /$ week or less. Furthermore, White et al (17) found that pain, measured using a visual analogue scale, did not predict whether individuals with arthritis met the recommended physical activity dose of $\geq 150 \mathrm{~min} /$ week. A difference between previous research using these measures and the present research is that our participants had to report experiencing some arthritis pain as an inclusion criterion. This inclusion characteristic may have made our sample distinct from samples in other research. Regardless, the finding that pain significantly differed between our exercise groups suggests that there may be beneficial painreducing effects of exercise for individuals achieving $\geq 150 \mathrm{~min} /$ week.

Of note, exercise group differences in both pain and pain acceptance may highlight the potential effectiveness of the latter psychosocial pain response. The conceptualization of pain acceptance by McCracken et al (29) does not suggest that pain acceptance precludes individuals from also experiencing pain. Rather, pain acceptance allows for engagement in valued activities despite the presence of pain. Findings support this contention, and further research is required to investigate the cause and effect relationship between acceptance and exercise.

Hierarchical multiple regression findings illustrated that the maintenance self-regulatory response was predicted solely by pain acceptance. The positive standardized beta illustrated that as acceptance increased, an associated increase in the use of the maintenance response occurred. The finding supports previous research illustrating the importance of pain acceptance to the performance of exercise among individuals with chronic disease $(13,41)$. Given the frequent reporting of this strategy in other arthritis-exercise research $(8,11)$ and current study findings, future investigation relative to the confrontation of pain anxiety is needed.

\section{Strengths and limitations}

There were limitations to the present study, despite its novel findings. First, although varied recruitment strategies were used, the sample was predominantly white and female, limiting the generalizability of the findings. Second, the online methodology may have excluded some individuals who would have met the participation inclusion criteria but could not participate (eg, lack of computer access to complete the online surveys). Third, the use of a one-item maintenance self-regulatory response can be argued to limit participant response options. However, given its frequent
TABLE 5

Differences in behavioural self-regulatory responses among participants who met versus did not meet the exercise dose

\begin{tabular}{lccc}
\hline Variable & Met dose $(\mathbf{n}=87)$ & $\begin{array}{c}\text { Did not meet } \\
\text { dose }(\mathbf{n}=49)\end{array}$ & Cohen's d \\
\hline $\begin{array}{l}\text { Adaptive self-regulatory } \\
\text { responses }\end{array}$ & $14.73 \pm 7.48$ & $16.67 \pm 8.19$ & 0.26 \\
$\begin{array}{l}\text { Maintenance self-regulatory } \\
\text { response }\end{array}$ & $5.53 \pm 2.26$ & $3.86 \pm 2.16$ & -0.73 \\
\hline
\end{tabular}

Data presented as mean $\pm S D$ unless otherwise indicated. Scale response were: adaptive self-regulatory responses, 0 to 40; and maintenance selfregulatory response, 0 to 8 , with higher scores representing more frequent use. Cohen's $d=$ effect size. Between-group differences within a row, ${ }^{*} P<0.01$

reporting in past arthritis-exercise literature, its inclusion was judged to be merited. Fuchs and Diamantopoulos (53) note that a one-item measure can be used when the construct is simple and single faceted, as appears to be the case with the maintenance response of simply performing the planned exercise, regardless of pain anxiety. Fourth, exercise was selfreported. However, we attempted to diminish the problematic recall of incidental minutes of exercise by focusing participants solely on $\geq 20 \mathrm{~min}$ of moderate to vigorous exercise. This focused recall of exercise correlates better with objective assessments than measures that have individuals report light-intensity and/or shorter bouts of exercise (33).

The strengths outweigh the limitations in the present initial study of pain anxiety and self-regulatory responses. First, the use of theoretical frameworks to guide the research - the social cognitive theory view of self-regulation and the fear-avoidance model - is a positive alternative to the criticism of atheoretical health-related research (54). Second, the study addressed recommendations to examine the fear-avoidance model using a motivational perspective that includes self-regulatory processes and pain acceptance (24). Third, recommendations to better understand psychosocial factors associated with adherence among individuals with arthritis were followed $(24,55)$. Fourth, the categorization of exercise groups by total exercise volume was guided by public health recommendations (1) and allowed for a comparison of newly investigated pain-related variables and self-regulatory responses. Understanding how those who exercised less differed from those who exercised more on psychosocial pain-related and behavioural response levels may help to identify problematic variables to target for change in those struggling to adhere to exercise via intervention (4).

\section{Future research}

Given the initial finding of moderation among an already-exercising sample, a next step is to determine whether the finding is more pronounced in other arthritis or experience contexts. For instance, future studies should recruit individuals with higher levels of pain anxiety, such as when individuals are experiencing an arthritis flare (ie, an exacerbation of typical arthritis symptoms, including pain) (56) and attempting to adhere to planned exercise. Also, individuals recently diagnosed with arthritis by a medical professional who are mostly inactive may be those with greater pain anxiety. Newly diagnosed individuals may not have the experience both with their disease and attempting to self-manage it through exercise (ie, attempting adaptive and/or maintenance selfregulation when challenged by pain anxiety) and, thus, may experience more pain anxiety. Within such samples, it would be important to continue to investigate pain acceptance given its positive association with greater exercise. Examining whether greater or lesser pain acceptance affects whether adults continue to exercise during a flare would be valuable. As well, examining whether pain acceptance levels make a difference among newly diagnosed individuals and whether they either confront and overcome their pain anxiety, or succumb and avoid exercise would be warranted.

Future research should continue to use and refine the newly developed self-regulatory responses measures. For example, although 
acceptable (38), the internal consistency of the adaptive self-regulatory responses measure showed room for improvement. Investigation of whether additional relevant items would enhance internal consistency could be undertaken (57). With regard to validity, although the measure used in the study had face and content validity, other aspects of validity could be examined.

In addition to the novel findings of the present study, information gleaned from the suggested research directions would offer insight for the targeted prescription of exercise, with emphasis on changing painrelated psychosocial and self-regulatory factors that contribute to exercise adherence and/or difficulties. For example, if pain acceptance is

\section{REFERENCES}

1. Public Health Agency of Canada, Centre for Chronic Disease Prevention and Control, \& Chronic Disease Surveillance Division. Life with arthritis in Canada: A personal and public health challenge. 2010. <www.phac-aspc.gc.ca/cd-mc/arthritis-arthrite/ lwaic-vaaac-10/index-eng.php> (Accessed October 19, 2014).

2. Centers for Disease Control and Prevention. Prevalence of doctordiagnosed arthritis and arthritis-attributable activity limitation: United States, 2007-2009. MMWR Morb Mortal Wkly Rep 2010;59:1261-5.

3. The Arthritis Foundation. Exercising with osteoarthritis: Physical activity is the best non-drug treatment for improving pain and function. 2014. $<$ www.arthritistoday.org/about-arthritis/types-of-arthritis/osteoarthritis/ daily-life/osteoarthritis-exercise.php> (Accessed October 19, 2014).

4. Bandura A. The primacy of self-regulation in health promotion. J Appl Psych Int Rev 2005;54,245-54.

5. Bandura A. Social Foundations of Thought and Action. New York: Prentice-Hall, 1986.

6. Baumeister RF, Heatherton TF, Tice DM. Losing Control. How and Why People Fail at Self-Regulation. San Diego: Academic Press, 1994.

7. Der Ananian CA, Wilcox S, Abbott J, et al. The exercise experience in adults with arthritis: A qualitative approach. Am J Health Behav 2006;30:731-44.

8. Der Ananian CA, Wilcox S, Saunders R, Watkins K, Evans A. Factors that influence exercise among adults with arthritis in three activity levels. Prev Chronic Dis 2006;3:1-16.

9. Wilcox S, Der Ananian C, Abbott J, et al. Perceived exercise barriers, enablers, and benefits among exercising and nonexercising adults with arthritis: Results from a qualitative study. Arthritis Rheum 2006;55:616-27.

10. Der Ananian C, Wilcox S, Watkins K, Saunders RP, Evans AE. Factors associated with exercise participation among adults with arthritis. J Aging Phys Act 2008;16:125-43.

11. Gyurcsik NC, Brawley LR, Spink KS, Brittain DR, Fuller DL, Chad K. Physical activity in women with arthritis: Examining perceived barriers and self-regulatory efficacy to cope. Arthritis Care Res 2009;61:1087-94.

12. Centers for Disease Control and Prevention. Physical activity and arthritis overview. Physical activity. The arthritis pain reliever. 2011. <www.cdc.gov/arthritis/pa_overview.htm\#3> (Accessed October 19, 2014).

13. Gyurcsik NC, Brawley LR, Spink KS, Glazebrook KE, Anderson TJ. Is level of pain acceptance differentially related to social cognitions and behavior? The case of active women with arthritis. J Health Psychol 2011;16:530-39.

14. Gyurcsik NC, Brawley LR, Spink KS, Sessford JD. Meeting physical activity recommendations: Self-regulatory efficacy characterizes differential adherence during arthritis flares. Rehabil Psychol 2013;58:43-50.

15. Eyler AA. Correlates of physical activity: Who's active and who's not? Arthritis Care Res 2013;49:136-40.

16. McCracken LM, Gutiérrez-Martínez O. Processes of change in psychological flexibility in an interdisciplinary group-based treatment for chronic pain based on acceptance and commitment therapy. Behav Res Ther 2011;49:267-74.

17. White DK, Tudor-Locke C, Felson DT, et al. Do radiographic disease and pain account for why people with or at high risk of knee osteoarthritis do not meet physical activity guidelines? Arthritis Rheum 2013;65:39-47.

18. Heuts PHTG, Vlaeyen JWS, Roelofs J, et al. Pain-related fear and daily functioning in patients with osteoarthritis. Pain 2004;110:228-35.

19. Strahl C, Kleinknecht RA, Dinnel DL. The role of pain anxiety, coping, and pain self-efficacy in rheumatoid arthritis patient functioning. Behav Res Ther 2000;38:863-73. further supported as helping individuals overcome their pain anxiety when needed (ie, when challenging), then an intervention component that may be worth investigating would be acceptance and commitment therapy plus exercise. Perhaps this type of intervention would encourage better adherence to the recommended exercise dose for arthritis selfmanagement compared with an intervention involving exercise alone.

FUNDING: This research was funded by a grant awarded by the Canadian Institutes of Health Research (CIHR) Regional Partnership Program with the Saskatchewan Health Research Foundation (SHRF).

20. Asmundson GJ, Vlaeyen JWS, Crombez G. Understanding and Treating Fear of Pain. New York: Oxford University Press, 2004.

21. Carleton RN, Asmundson GJ. The multidimensionality of fear of pain: Construct independence for the Fear of Pain QuestionnaireShort Form and the Pain Anxiety Symptoms Scale-20. J Pain 2009;10:29-37.

22. Leeuw M, Goossens ME, Linton SJ, Crombez G, Boersma K, Vlaeyen JW. The fear-avoidance model of musculoskeletal pain: Current state of scientific evidence. J Behav Med 2007;30:77-94.

23. Lethem J, Slade PD, Troup JD, Bentley G. Outline of a fear-avoidance model of exaggerated pain perception-I. Behav Res Ther 1983;21:401-8.

24. Crombez G, Eccleston C, Van Damme S, Vlaeyen JW, Karoly P. Fear-avoidance model of chronic pain: The next generation [Special Topic Series]. Clin J Pain 2012;28:475-83.

25. Slade PD, Troup JD, Lethem J, Bentley G. The fear-avoidance model of exaggerated pain perception-II: Preliminary studies of coping strategies for pain. Behav Res Ther 1983;21:409-16.

26. Vlaeyen JW, Linton SJ. Fear-avoidance and its consequences in chronic musculoskeletal pain: A state of the art. Pain 2000;85:317-32.

27. Vlaeyen JW, Kole-Snijders AM, Boeren RG, van Eek H. Fear of movement/(re)injury in chronic low back pain and its relation to behavioral performance. Pain 1995;62:363-72.

28. Esteve R, Ramírez-Maestre C. Pain fear avoidance and pain acceptance: A cross-sectional study comparing their influence on adjustment to chronic pain across three samples of patients. Ann Behav Med 2013;46:169-80.

29. McCracken LM, Vowles KE, Eccleston C. Acceptance of chronic pain: Component analysis and a revised assessment method. Pain 2004;107:159-66.

30. Cho S, McCracken LM, Heiby EM, Moon D-E, Lee J-H. Pain acceptance-based coping in complex regional pain syndrome type I: Daily relations with pain intensity, activity, and mood. J Behav Med 2013;36:531-38.

31. McCracken LM, Spertus IL, Janeck AS, Sinclair D, Wetzel FT. Behavioral dimensions of adjustment in persons with chronic pain: Pain-related anxiety and acceptance. Pain 1999;80:283-9.

32. Hagger MS, Wood CW, Stiff C, Chatzisarantis NL. Self-regulation and self-control in exercise: The strength-energy model. Int Rev Sport Exerc Psychol 2010;3:62-86.

33. Barbour KE, Helmick CG, Theis KA, Murphy LB, Hootman JM, Brady TJ. Prevalence of doctor diagnosed-arthritis and arthritisattributable activity limitation: United States, 2010-2012. Morb Mortal Wkly Rep 2013;62:869-73.

34. Centers for Disease Control and Prevention. Data \& statistics. FAQs (data related) case definition: Is self-reported information on the type of arthritis valid? 2011. <www.cdc.gov/arthritis/data_ statistics/faqs/case_definition.htm $\# 5>$ (Accessed October 19, 2014).

35. Cust AE, Smith BJ, Chau J, et al. Validity and repeatability of the EPIC physical activity questionnaire: A validation study using accelerometers as an objective measure. Int J Behav Nutr Phys Act 2008;5:33.

36. Matthews CE, Ainsworth BE, Hanby C, et al. Development and testing of a short physical activity recall questionnaire. Med Sci Sports Exerc 2005;37:986-94.

37. Hadjistavropoulos T, Herr K, Turk DC, et al. An interdisciplinary expert consensus statement on assessment of pain in older adults. Clin J Pain 2007;(23 Suppl):1-43.

38. Field AP. Discovering Statistics With SPSS, 2nd edn. London: Sage, 2005.

39. McCracken LM, Dhingra L. A short version of the Pain Anxiety Symptoms Scale (PASS-20): Preliminary development and validity. Pain Res Manag 2002;7:45-50. 
40. Roelofs J, McCracken LM, Peters ML, Crombez G, van Breukelen G, Vlaeyen JW. Psychometric evaluation of the Pain Anxiety Symptoms Scale (PASS) in chronic pain patients. J Behav Med 2004:27:167-183.

41. Rejeski JW, Tian L, Liao Y, McDermott MM. Social cognitive constructs and the promotion of physical activity in patients with peripheral artery disease. J Cardiopulm Rehabil Prev 2008;28;65-72.

42. Larsen DK, Taylor S, Asmundson GJG. Exploratory factor analysis of the Pain Anxiety Symptoms Scale in patients with chronic pain complaints. Pain 1997;69:27-34.

43. United States Department of Health and Human Services. 2008 physical activity guidelines for Americans. Be active, health, and happy! (ODPHP Publication No. U0036). 2008. <www.health.gov/ paguidelines/pdf/paguide.pdf> (Accessed October 19, 2014).

44. Nelson ME, Rejeski WJ, Blair SN, et al. Physical activity and public health in older adults: Recommendations from the American College of Sports Medicine and the American Heart Association. Med Sci Sports Exerc 2007;39:1435-45.

45. Tabachnik BG, Fidell LS. Using Multivariate Statistics, 6th edn. Boston: Pearson/Allyn \& Bacon, 2012.

46. Aiken LS, West SG. Multiple regression: Testing and Interpreting Interactions. Thousand Oaks: Sage, 1991.

47. Evans MG. The problem of analyzing multiplicative composites: Interactions revisited. Am Psychol 1991;46:6-15.

48. Frazier PA, Tix AP, Barron KE. Testing moderator and mediator effects in counseling psychology research. J Couns Psychol 2004;51:115-34.
49. Cohen J. Statistical Power Analysis for the Behavioral Sciences, 2nd edn. New York: Lawrence Erlbaum Associates, 1988.

50. Baumeister RF, Heatherton TF. Self-regulation failure: An overview. Psychol Inq 1996;7:1-15.

51. Baumeister RF. Ego depletion and self-control failure: An energy model of the self's executive function. Self Identity 2002;1:129-36.

52. Thibodeau MA, Welch PG, Katz J, Asmundson GJ. Pain-related anxiety influences pain perception differently in men and women: A quantitative sensory test across thermal pain modalities. Pain 2013;154:419-26.

53. Fuchs C, Diamantopoulos A. Using single-item measures for construct measurement in management research: Conceptual issues and application guidelines. Digital Book World 2009;2:195-210.

54. Painter JE, Borba CP, Hynes M, Mays D, Glanz K. The use of theory in health behavior research from 2000 to 2005: A systematic review. Ann Behav Med 2008;35:358-62.

55. Alliance for the Canadian Arthritis Program. Report from the summit on standards for arthritis prevention and care. 2006. $<$ www.arthritisalliance.ca/docs/SAPC\%20Full\%20Report\%20 20060331\%20en.pdf> (Accessed October 19, 2014).

56. Bingham CO III, Pohl C, Woodworth TG, et al. Developing a standard definition for disease "flare" in rheumatoid arthritis (OMERACT 9 Special Interest Group). J Rheumatol 2009;36:2335-41.

57. Clark LA, Watson D. Constructing validity: Basic issues in objective scale development. Psyhcol Assess 1995;7:309-19. 


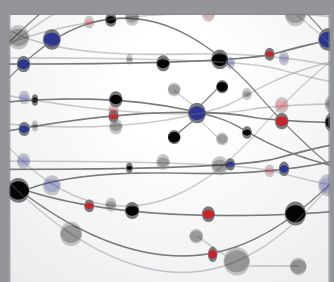

The Scientific World Journal
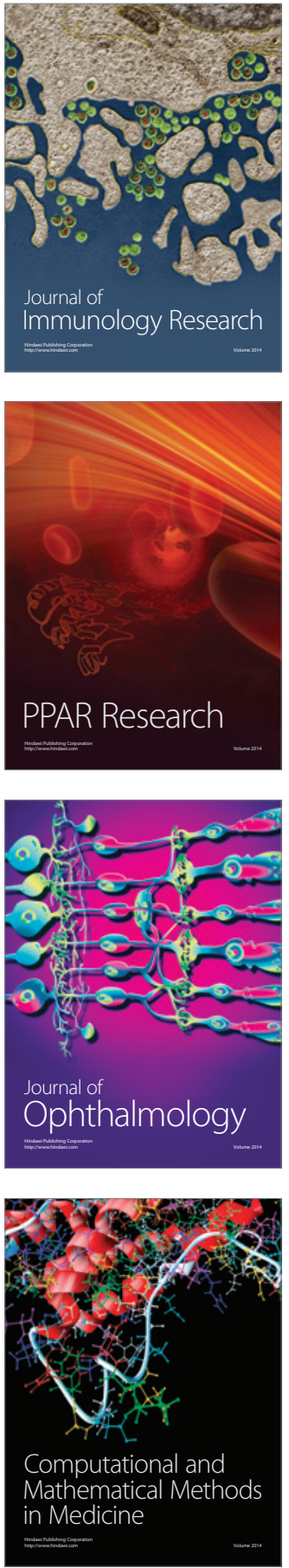

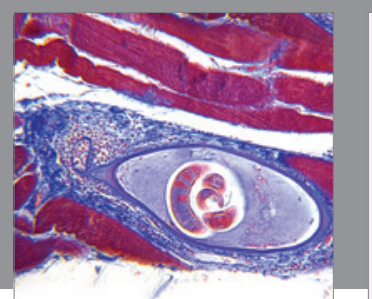

Gastroenterology Research and Practice

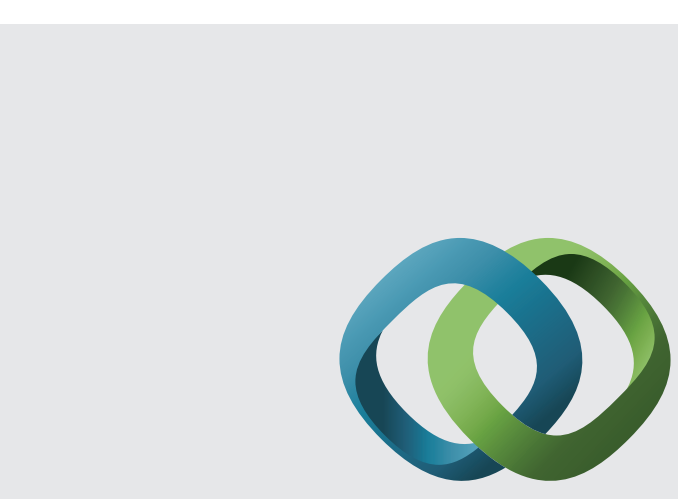

\section{Hindawi}

Submit your manuscripts at

http://www.hindawi.com
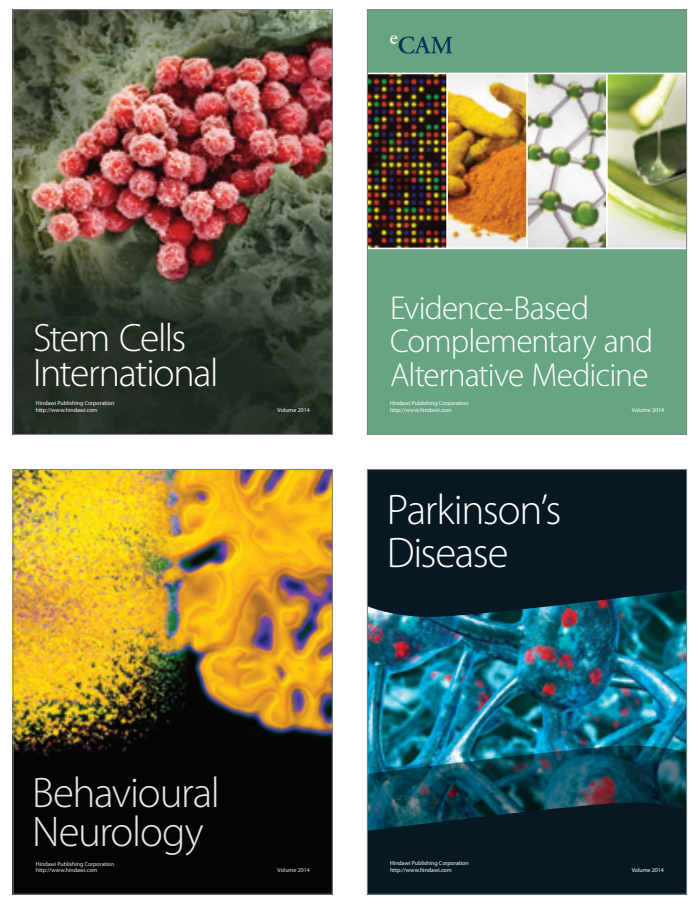
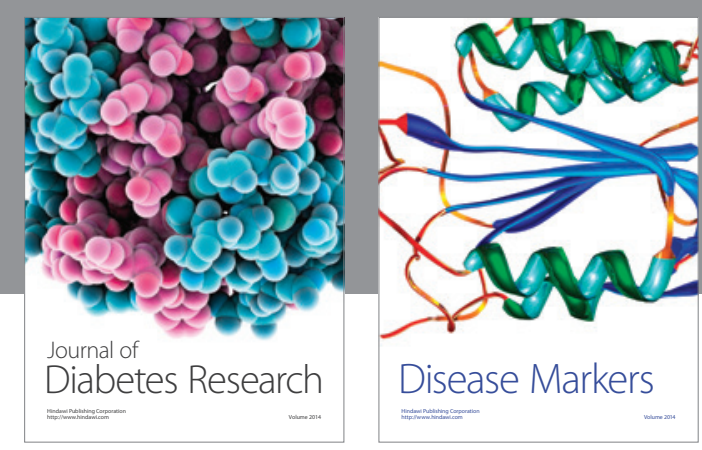

Disease Markers
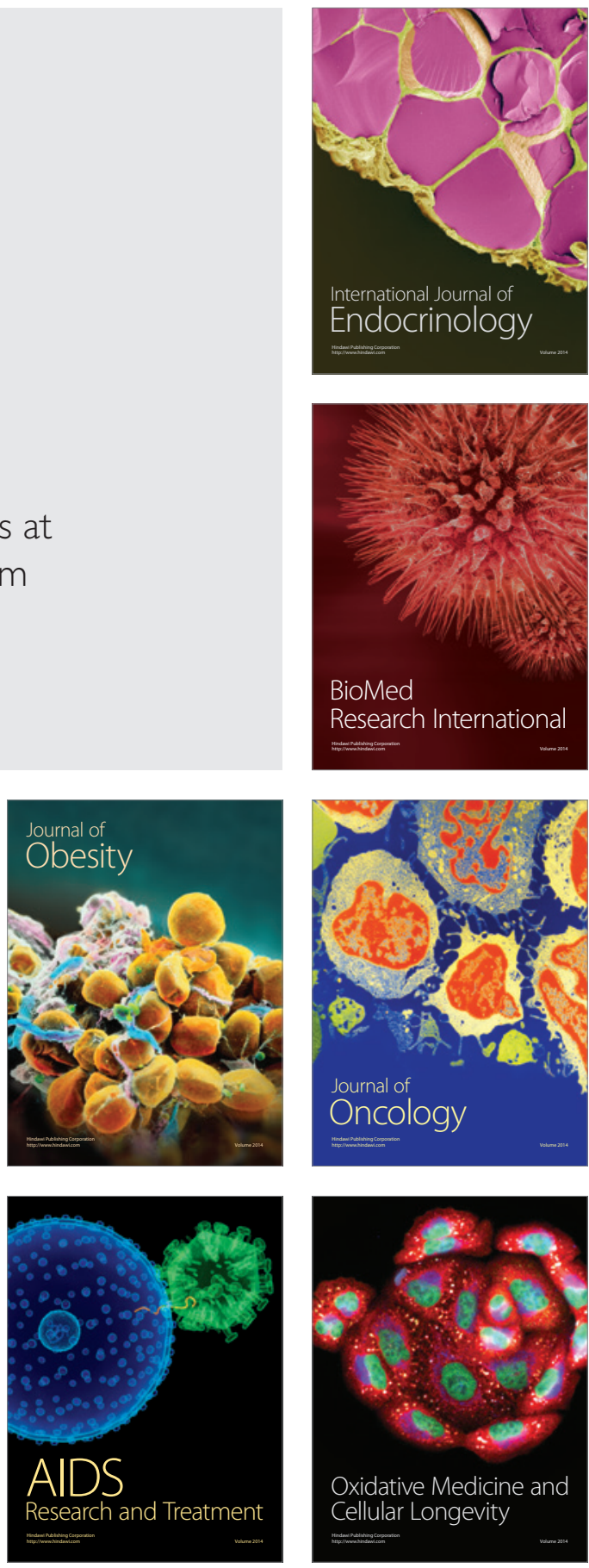